\title{
LEITURAS DA TECNO-ARTE-POESIA
}

Jorge Luiz Antonio Universidade Estadual de Campinas (IEL-UNICAMPI) jlantonio@uol.com.br

\section{Introdução}

A civilização da imagem preconizada por Moles (2005) em 1969 já está nos meios digitais. A transformação da escrita, de que fala Flusser (2010), em obra de 1987, já é um conjunto de bibliotecas em programas como Adobe Photoshop e CorelDraw atuais. Imagens não referenciais são os ícones com os quais a época das tecnologias móveis e da nanotecnologia convive cotidianamente. Como ler essas transformações? Como nos situarmos nessa floresta de signos não verbais que, em muitos casos, para não dizer em sua grande maioria, significam muito em nossa comunicação cotidiana? Quais os critérios para ler essas inovações quando usadas em processos criativos?

Esse universo em formação e crescimento constante pede novas leituras. Os meios digitais trazem novos questionamentos sobre a nossa forma de criar, pensar, comunicar. Com o desenvolvimento dos meios digitais, novos critérios de leitura vêm sendo apontados por estudiosos que tratam das relações entre leitura e cultura digital, da leitura na rede e da leitura do texto digital. Como ler esses textos que circulam nos meios digitais? Como entendê-los adequadamente? Por se tratar de uma abordagem bastante ampla, parece adequado delimitar a leitura a uma tipologia de textos digitais e, assim, mapear simultaneamente o que vem sendo produzido. 
Várias obras criativas ${ }^{1}$ e teóricas estão surgindo e propondo diferentes leituras que nos auxiliam a compreender esse fenômeno contemporâneo em seus vários percursos possíveis: tecnociência e cultura (Araújo, 1998), cultura e estética tecnológica (MOLES, 1973; MORAES, 2001; SANTAELLA, 2007), arteciência (CAMPOS, R. A., 2003), cultura digital, cibercultura, cultura em fluxo (LÉVY, 1999; COSTA, 2002; SANTAELLA, 2003; BRASIL; FALCI; JESUS; ALZAMORA, 2004), cultura da interface (JOHNSON, 1997), arte, ciência e tecnologia (DOMINGUES, 1997, 2003, 2009; MACIEL; PARENTE, 2003); arte da cibercultura, ciberarte ou arte digital (MOLES; ANDRÉ, 1971; POPPER, 1993; PLAZA; TAVARES, 1998; Ciberliteratura, Literatura Eletrônica ou Literatura Digital (VUILLEMIN, 1990; BARBOSA, 1996; PAJARES TOSCA, 2004).

Há também estudos sob outros enfoques: os gêneros textuais (MACHADO, 2002, p. 71-81), hipertexto e gêneros digitais (MARCUSCHI; XAVIER, 2005); a interação na internet como novas formas de usar a linguagem (ARAÚJO; BIASI-RODRIGUES, 2005), internet e ensino, novos gêneros e outros desafios (ARAÚJO, 2007).

Para isso, os saberes interdisciplinares são importantes, como, por exemplo, o conhecimento das tecnologias digitais, das artes, do design para compreender o texto digital / eletrônico ou o hipertexto / a hipermídia em seus processos criativos artísticos, literários e poéticos, dentre os quais os denominados de poesia digital, poesia eletrônica ou tecno-arte-poesia, também conhecidos por poesia hipertextual, poesia hipermídia ou ciberpoesia.

As leituras da tecno-arte-poesia compreendem muitos aspectos, autores, teorias, enfoques e conjunto de obras escolhidas, dentre outros critérios. Apresentar sucintamente essas análises demandaria a publicação de um ou mais livros, após muitos anos de pesquisa. Se o estudo ficar restrito às publicações impressas nas línguas mais lidas no Brasil, além do português (espanhol, catalão, galego, francês, italiano, romeno, inglês, alemão, por

\footnotetext{
${ }^{1}$ As obras criativas, em si mesmas, mais seus manifestos, prefácios, apresentações, notícias e/ou resenhas são leituras que desencadeiam reflexões válidas.
}

Texto Digital, Florianópolis, v. 7, n. 2, jul./dez. 2011. ISSNe: 1807-9288 
exemplo), já teríamos uma quantidade significativa. Se incluirmos os capítulos de livros e os artigos em publicações impressas e digitais, essa amostra se ampliaria mais, pois novos textos aparecem constantemente.

A opção mais adequada seria apresentar um panorama das leituras possiveis da tecno-arte-poesia, resultado de uma série de reflexões a partir de um objeto de estudo desde 1996. Mesmo sem a pretensão de chegar a uma unidade, esta pesquisa oferece uma coletânea de reflexões, que foram revisadas, atualizadas e reescritas.

Em 1969, Moles afirmou que "muitas vezes já se disse que a civilização contemporânea era a civilização da imagem, que era o que ela tinha de mais específico em relação a todas as civilizações passadas. $O$ termo contraditório de civilização oral proposto para descrever o novo universo da comunicação é ainda tão-somente uma imagem do futuro, pois repousa num substrato técnico: gravador, máquina de ouvir, máquina de falar, que se encontram em processo de desenvolvimento, seja industrial, seja técnico, e cujas consequências sociais efetivas não se fizeram ainda sentir (2005, p. 15).

O "termo contraditório de civilização oral proposto para descrever o novo universo da comunicação", que Moles considera como "imagem do futuro", parece referir-se a obras como A Galáxia de Gutenberg (MCLUHAN, 1972), que preconiza a oralidade da Era Eletrônica.

\section{Estado de arte das leituras}

O estudo na linha do tempo nos mostra um percurso do pensamento sobre as mais variadas tipologias do texto digital, conforme exemplos: Para navegar no século 21: Tecnologias do imaginário e cibercultura (Martins; Silva, 2000); Os arquivos imperfeitos: Memória social e cultura eletrônica (Colombo, 1991), Hypertext: The Convergence of Contemporary Critical Theory and Technology (LANDOW, 1992), The Digital Word: Text-Based Computing in the Humanities (LANDOW; DELANY, 1993), Hypermedia and Literary Studies (DELANY; LANDOW, 1994), Multimedia and Hypertext: The Internet and beyond 
(NIELSEN, 1995), Texto, hipertexto, hipermedia (LAUFER; SCAVETTA, [199...]. Mesmo tratando de tecnologias em desuso hoje, a reflexão permanece válida, em sua grande maioria, para as tecnologias em uso nos dias atuais. Dessa forma, podemos observar o livro Typewriter Art (RIDDELL, 1975) e ficar admirado com os recursos da máquina de escrever e podemos comparar com o que o computador pôde fazer, desde os seus primórdios. Também vale lembrar o caso de The Computer Artist's Handbook: Concepts, Techniques, and Applications (SCHWARTZ, L. F.; SCHWARTZ, L. R., 1992), que trata da obra de Lillian Feldman Schwartz, uma pioneira da Arte Computacional nos EUA nos anos de 1960/1970, que também fez algumas criações poéticas significativas.

Com o desenvolvimento dos meios digitais, novos critérios de leitura vêm sendo apontados por estudiosos que tratam da leitura na rede, da leitura do texto digital e das relações entre leitura e cultura digital, que motivaram obras como: Ler e navegar (MARINHO, 2001), Práticas leitoras para uma cibercivilização (RÖSING; RETTENMAIER, 2007; vários volumes), Leitura da arte e arte da leitura (RÖSING; RETTENMEIER, 2009), A leitura nos oceanos da internet (Silva, 2008), Questões de literatura na tela (RETTENMAIER; RÖSING, 2010), Leitura e escritura em movimento (RIBEIRO; VILELA; COURA SOBRINHO; SILVA, 2010). Esses livros tratam de diferentes tipos de textos digitais, mas também há estudos especializados sobre narrativas digitais, literatura digital, poesia digital, etc.

Um estudo interdisciplinar começa a se fazer necessário, sob o ponto de vista da Teoria, História e Crítica Literária. É o caso, por exemplo, de estudar as relações entre a teoria literária, as artes, o design e as tecnologias, como são os casos de "Literatura e outras artes" (WELLEK; WARREN, [s.d.], p. 153-166), "Entrada de la cibernetica" (TORRE, 1974b, p. 283-284), etc. O mesmo critério vale para a leitura da poesia digital, conforme detalhamentos apresentados em outras partes deste estudo. É importante mapear as leituras existentes e estabelecer um percurso. 
Esse interesse faz parte de departamentos universitários e instituições culturais, cujo exemplo é a instituição da Bolsa Funarte de Produção Crítica sobre Conteúdos Artísticos em Mídias Digitais / Internet, em agosto de $2009^{2}$, cujo resultado será apresentado em breve, tão logo os bolsistas possam publicar seus estudos. Esse concurso do MEC FUNARTE foi "O aperfeiçoamento da formação de críticos de arte no país, voltados para as mídias digitais/internet, a partir da concessão de bolsas", pois criou "condições materiais para que a especialização profissional e a produção de conhecimento acerca da atual arte brasileira amplie o acesso e a reflexão crítica e teórica dos conteúdos". O edital do concurso para a bolsa conceituou "conteúdos artísticos em mídias digitais /internet toda a produção relacionada a artes visuais, dança, circo, teatro, performance, fotografia, música, audiovisual e literatura, baseada em computadores e suas possíveis extensões, cujo armazenamento, difusão e/ou exposição também se baseiam nessas tecnologias. Entre os suportes conhecidos estão os websites (páginas na internet), CD-Rom, DVD, DVD-Rom, computadores intermediados por monitores ou projetores (datashow), reprodutores de conteúdo audiovisual (mp3, mp4 e outros formatos), computadores de mão (palm tops) e telefones celulares". Foram concedidas bolsas de duração de seis meses, com uma ajuda financeira adequada para o desenvolvimento das pesquisas.

Cada obra que surge com nova proposta criativa é um desafio ao pesquisador e aos seus leitores. É por isso que a Teoria, a História e a Crítica Literária são interdisciplinares: elas precisam de outras disciplinas para iluminar, compreender e interpretar o seu objeto de estudo.

Dentre as criações artísticas, literárias e poéticas contemporâneas que oferecem constantes desafios aos seus fruidores, estudiosos e pesquisadores, está a poesia eletrônica, também chamada de ciberpoesia / poesia digital ou tecno-arte-poesia. Trata-se de um tipo de poesia contemporânea, dentre as variedades e produções da poesia dos meios impressos, com renovações significativas, que desafia a compreensão do leitor / ciberleitor, principalmente

\footnotetext{
${ }^{2}$ Disponível em: < http://www.cultura.gov.br/site/2009/07/01/bolsa-funarte-de-producao-criticasobre-conteudos-artisticos-em-midias-digitais-internet/>. Acesso em: 10 nov. 2011.
}

Texto Digital, Florianópolis, v. 7, n. 2, jul./dez. 2011. ISSNe: 1807-9288 
porque faz parte de vários suportes, meios e áreas (artes, design, tecnologias e poesia).

Este artigo representa um primeiro esforço no sentido de mapear algumas leituras existentes sob enfoques teóricos diferentes, mas que se faz necessário apontar, e tem por objetivo estabelecer um percurso das relações da poesia com as Artes, o Design e as Novas Tecnologias no momento em que começa a haver uma fusão entre elas, fenômeno que começa a ser notado no final do século XIX, início do século XX (vanguardas) e se define claramente a partir da década de 1950 em diante. É dentro desse contexto que surge a poesia eletrônica, poesia digital, poesia-imagem-som-hipermídia-interativa, "nova poesia verbo-áudio-moto-visual" (MACHADO, 2000, p. 209), ou tecno-artepoesia, que vai florescer paralela e simultaneamente com a poesia concreta e a visual, e vai existir essencialmente primeiro em computadores isolados desde 1959 e nas redes digitais a partir de 1995, ano em que se desenvolvem as experimentações poéticas e artísticas na web.

Trata-se, pois, do estudo de uma migração da poesia para diversos meios e suportes: da página do livro para as salas de exposição, dividindo espaço com as artes visuais; do meio bidimensional da página para o tridimensional das instalações e das esculturas, e do meio impresso, de um modo geral, para o meio eletrônico, assunto central deste estudo. Essa migração compreende algumas transformações que as novas linguagens (artísticas e tecnológicas) influenciam.

Em se tratando de uma poesia que se constrói com palavras, grafismos, imagens estáticas e animadas e sons nos meios digitais, torna-se necessário analisar os procedimentos dessa construção por meio das suas dimensões gráficas, visuais, cinéticas e sonoras e, também, utilizar uma denominação conceitual para esse tipo de poesia, que é uma continuação das poesias já existentes e que se configura num outro formato, gênero ou tipo: tecno-artepoesia $^{3}$ é uma síntese mais significativa para mostrar as dimensões gráficas,

\footnotetext{
${ }^{3}$ Há inúmeras denominações para esse tipo de poesia. Listamos cerca de oitenta nomes (ANTONIO, 2005) e concluímos que, para cada tipo de tecnologia computacional, há uma
} 
no campo do Design Gráfico e/ou Digital, visuais (Artes Visuais), cinéticas (Cinema e Vídeo) e sonora (Música, Engenharia e Tecnologia do Som).

A tecno-arte-poesia, poesia eletrônica ou poesia digital só pode ser adequadamente compreendida se tivermos como parâmetros a análise dos procedimentos que essas dimensões mostram: artísticas (visuais, cinéticas e sonoras) e computacionais (meios digitais, hipertextualidade, interatividade, processo colaborativo e hipermidialidade).

Olhar a sua origem e compará-la com a poesia do início do século $X X$ é uma forma de entender um percurso que esses primórdios apontam, mas não o realizam plenamente.

Com base nas relações entre poesia e visualidade, poesia e tecnologia comunicacional e poesia e tecnologia computacional, a seleção de poemas apresenta poucos exemplos do século XIX e da primeira metade do século XX, pois se concentra na produção compreendida dos anos 1959 até os dias atuais.

Uma análise rica poderia ser a adoção, por exemplo, do conceito de lexia: "estrelar o texto, separando, como faria um pequeno sismo, os blocos de significação cuja leitura capta apenas a superfície lisa, imperceptivelmente soldada pelo fluxo das frases, o discurso fluente da narração, a grande naturalidade da linguagem corrente. O significante de apoio será recortado em uma seqüência de curtos fragmentos contíguos, que aqui chamaremos de lexias, já que são unidades de leitura” (BARTHES, 1992, p. 47). Analisar as lexias verbais e visuais e explorar a riqueza de significação sonora e de movimento potencialmente apresentados nos levaria a entender os caminhos da poesia visual impressa. Compreender as lexias verbais, visuais (animadas e estáticas) e sonoras, juntamente com os recursos das hiperligações (hyperlinks) ou ligações (links) que oferecem a hipertextualidade (a escolha de lexias produzindo diferentes significados) e permitem uma interatividade do

denominação particular. Os estudos acadêmicos costumam usar ciberpoesia, poesia digital ou poesia eletrônica, mas eles são apenas escolhas, ao invés de generalizações adequadas de um fazer poético com os computadores. 
leitor-operador com a poesia eletrônica em construção a partir dos cliques, escolhas de lexias metafóricas e metonímicas: isso nos traria uma pluralidade de significados e mostraria, com certeza, a riqueza da poesia eletrônica.

\section{Poesia, meios, suportes, tecnologias}

Podemos ler poesia nos livros, apreciá-la em eventos performáticos, ouvi-la do próprio poeta ou em algum aparelho eletrônico, tocá-la em algumas instalações poéticas, e também "lê-la" ao computador, acessando CD-Rom, DVD, disco flexível, pendrive, e-reader, tablet, Internet ou web.

Antigamente íamos a saraus e assistíamos a declamações acompanhadas ao piano. Alguns poetas aproveitavam as reuniões sociais e culturais (teatro, ópera, clubes, etc.) para fazer da poesia um evento de divulgação de idéias revolucionárias, ou algumas experimentações poéticas.

A poesia falada pelo próprio poeta ou por um intérprete pôde ficar registrada nos gravadores de sons (fita cassete, disco vinil, cd, etc.) e ser divulgada posteriormente, a exemplo dos livros impressos. Também a poesia falada pôde ser transmitida, ao vivo ou gravada, através do rádio, da televisão, do vídeo e do filme. Hoje esse material está disponível nos meios digitais.

Com muito alarde, as vanguardas históricas nos trouxeram as mais diferentes formas de fazer poesia, que até hoje vêm sendo re-utilizadas nos mais diferentes meios. Os poetas escreveram isoladamente e também publicaram obras coletivas, como O Perfeito Cozinheiro das Almas Deste Mundo (Oswald de Andrade, 1918), Minutes to Go (William Burroughs, Brion Gysin, Sinclair Beiles e Gregory Corso, 1960), dentre outras.

As artes, a ciência, a técnica e a tecnologia trouxeram novas inspirações ao poeta, que decidiu intervir nesses outros saberes e transformá-los em poesia. A imaginação do poeta e a sua capacidade de negociação com as tecnologias são notáveis e surpreendentes ao longo do tempo. Vem-nos à mente o banquete de Camões servido com trovas (século XVI) e a instalação poética 
"Festim de Camões", de Regina Vater (2001). A poesia com recursos matemáticos do Oulipo (Ouvroir de Littérature Potentielle), o Cent mille milliards de poèmes (Raymond Queneau, 1961) e suas versões em programas computacionais. A PO.EX/80 (Poesia Experimental Portuguesa) na qual poemas foram criados a partir das medidas dos visitantes voluntários, obtidas em uma fita létrica (E. M. de Melo e Castro, 1980). E as primeiras experiências de Théo Lutz fazendo "auto poems" com um programa de computador (1959). E muitos outros exemplos.

A poesia hoje pode ser apreciada pelo olhar, já que a visualidade também faz parte dela. Antes era formada apenas de palavras que evocavam sons e imagens (logopéia, fanopéia, melopéia, de Pound). Palavra que evoca a imagem, depois ela própria vai se tornando imagem na folha de papel (ou no espaço tridimensional da instalação ou performance). A busca constante leva à inclusão da imagem visual que se junta, ou não, à palavra, para se transformar em poesia visual, para ser lida, vista e ouvida, tornando-se um texto verbi-vocovisual.

Duas grandes afirmações do século $X X$ nos ajudam a entender a poesia visual e eletrônica que costumamos "ler" nos vídeos, disquetes, sítios, na Internet, nos dvds e/ou nos cd-roms da Era Digital.

Primeira - $\mathrm{O}$ "caráter estético (da língua poética) se revela sempre pelos mesmos signos: é criado conscientemente para libertar a percepção do automatismo; sua visão representa o objetivo do criador e ela é construída artificialmente de maneira que a percepção se detenha nela e chegue ao máximo de sua força e duração" (CHKLOVSKI, 1971, p. 54).

Segunda - É a força de representação da literatura, o fato de que o homem não "pode fazer coincidir uma ordem pluridimensional (o real) e uma ordem dimensional (a linguagem)" (BARTHES, 1995, p.22), ou seja, a função utópica da literatura. 
É a poesia saindo de si mesma, das suas fontes (a palavra), para participar de outras artes (visuais, sonoras, cinéticas), das ciências e das tecnologias.

Os poemas abaixo nos ajudam a entender essa procura utópica da literatura, isto é, o fato da literatura tentar ser o próprio real e, consequentemente, chegar à poesia visual e à eletrônica contemporâneas.

\section{A música e a letra}

Os pássaros pousados na pausa dos fios do telégrafo, Eles é que vão sucessivamente improvisando - um após outro A letra e a música dos ventos...

Mário Quintana (1992, p. 39)

\section{Geometrias variáveis}

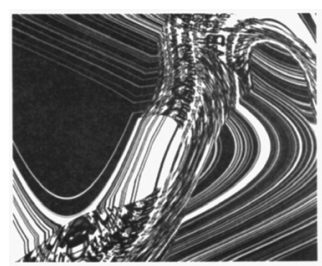

E. M. de Melo e Castro (1998, p. 69)

\section{Soneto de outono}

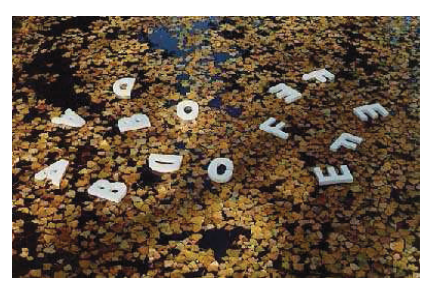

Fernando Aguiar (1991, p.s.n.)

Dentre os motivos muitos fortes que conduzem o poeta a trilhar caminhos tão singulares, estão a transgressão, a subversão de funções da linguagem (Jakobson) e a necessidade de fazer um poema especial, que contenha em si a própria realidade, que não seja apenas a representação. 
A imagem trouxe ao poema a sua "realidade" visual, de certa forma substituindo a descrição e produzindo o que pode ser chamado de poesia visual. As tecnologias eletrônicas e computacionais possibilitaram a inclusão da palavra, do som, da imagem e da animação num mesmo meio e, assim, pôde surgir uma poesia que recebeu diferentes denominações, mas todas englobadas no termo "tecno-poesia".

Assim, por exemplo, um poeta lança palavras de isopor num rio e as fotografa, fixando essas palavras no filme de sua máquina, para depois assumir essas imagens como fotopoemas; ou subverte as funções pragmáticas das tecnologias computacionais, transformando os registros eletrônicos em elementos poéticos, usando o texto eletrônico, as interfaces, a interatividade e a hipertextualidade, como é o caso da poesia eletrônica que se encontra na WWW.

Essa vontade de subverter acompanha o homem, também o poeta, desde o primeiro desenho na caverna com a intenção de "segurar" o animal, desenhando-lhe a imagem, e talvez sobreviva numa espécie de vodu não religioso, mas simbólico, que é a tentativa de segurar a realidade na representação parcial, unidimensional, dela. O poeta quer que o real coincida com a linguagem, mesmo tendo plena consciência de que são opostas, distantes, irreconciliáveis. Hoje o poeta pratica esse "vodu", "segurando" a sua poesia no monitor de um PC, subvertendo tudo o que for possível para fazer do ciberespaço uma forma de comunicação poética, que é a sua poesia eletrônica.

Quatro sítios que reúnem as poesias visuais e eletrônicas oferecem uma visão panorâmica e particular do que vem sendo produzido no Brasil e no mundo.

Vispo.com (http://www.vispo.com), sítio do canadense Jim Andrews, oferece não só a vasta obra do poeta e do programador (poesia verbal, visual, sonora, eletrônica, ensaios), mas também a página Poetry - New Media: Links of Imagination, que é uma antologia internacional da arte e da poesia eletrônicas, bem como a página VISPO Guests, espaço destinado a outros poetas e artistas. O título do sítio "Vispo" indica a síntese principal: a linguagem e a 
imagem, a poesia visual - vi(sual)po(etry) - da era da poesia visual, animada e sonora da web.

A obra de Andrews é vasta e está em constante crescimento. Além da obra do autor, que certamente agradará os leitores eletrônicos, a parte "Vispo Guests" (Convidados de Vispo) traz uma série de poetas de outros países, como Dan Waber (EUA), Clemente Padin (Uruguai), Ted Warnell, etc. Em "Poetry - New Media: Links of Imagination" (Poesia - Novas Mídias - Linques da Imaginação) tem-se uma web-bibliografia comentada, de valor inestimável para os apreciadores e estudiosos do assunto.

Brazilian Digital Art and Poetry on the Web foi uma compilação iniciada em 2000, por sugestão de Jim Andrews. Está hospedada no sítio Vispo.com (http://www.vispo.com/misc/BrazilianDigitalPoetry.htm) e mapeia a arte e a poesia brasileiras no ciberespaço. Este sítio foi o resultado de um diálogo com Jim Andrews, autor de "Vispo.com". Ao ingressar no egroup Webartery, que foi coordenado por Jim Andrews (Canadá) e agrupa cerca de 200 artistas e poetas digitais de muitos países, veio o convite para falar sobre a arte e poesia digitais brasileiras.

A procura de artistas e poetas na web resultou em "Brazilian Digital Art and Poetry on the Web", que foi anunciado na Internet e publicado na web em novembro de 2000, e vem se atualizando constantemente e tornou-se uma referência (inter)nacional.

Esse mapa de linques abrange boa parte da poesia verbal, visual e digital no Brasil e tem diversos desdobramentos através de outros sítios, como é o caso de "Brazilian Visual Poetry", evento sob a curadoria de Regina Vater, que contém uma quantidade significativa de poesia verbal.

O uso da língua inglesa foi a forma mais adequada de divulgar o sítio, pois, como disse o designer gráfico Miguel de Frias, em conversa informal, o inglês é o esperanto que deu certo. 
Brazilian Visual Poetry - http://www.imediata.com/BVPI - é um registro eletrônico da exposição de Poesia Visual Brasileira sob a curadoria de Regina Vater, no Mexic-Arte Museum, em Austin, no Texas, EUA (18 de janeiro a 18 março de 2002), com a participação de 53 poetas brasileiros. Nesse sítio encontra-se a instalação "Festim de Camões / Camoes' Feast", com poemas de Affonso Romano de Sant'Anna, Antonio Cícero, Caetano Veloso, Frederico Barbosa, Haroldo de Campos, Manoel de Barros, Olga Savary e Sérgio de Castro Pinto.

\section{Introdução à Poesia Eletrônica}

Como partes das atividades humanas, a ciência, a tecnologia e a técnica sempre mantiveram relações, amistosas ou não, com a arte, a literatura e a poesia.

Artistas e escritores, sendo também cientistas, tecnólogos e técnicos, ou não, como seres integrados à sua época, tomaram conhecimento, retomaram os temas e métodos da ciência e os transformaram em atividades artísticas, literárias ou poéticas.

A poesia, como arte da palavra, também se sentiu atraída pela ciência, pela tecnologia e pela técnica, e as fez aliadas na busca de uma comunicação mais eficiente, na tentativa de realizar aquilo que Roland Barthes denominou de função utópica da literatura.

Assim, temos o soneto, que mantém proporções matemáticas (quatorze versos, quatro estrofes, mesmo número de sílabas métricas, rimas, etc); uma espécie de filosofia da composição na obra de Edgard Allan Poe (1987, p. 109122); a poesia realista, que usa método e vocabulário científicos, as inovações científicas e tecnológicas, como fonte de inspiração, na busca da fusão dos códigos verbais, sonoros, visuais, cinéticos; com a Teoria da Informação e a Linguística, no século $X X$, surge uma arte permutacional, com base em processos estatísticos, matemáticos, algorítmicos, que, com o computador, chega a uma "computer poetry" e as suas mais variadas características; os 
estudos linguísticos possibilitaram a criação de uma linguagem simbólica, que se adaptou à linguagem de programação; o contato do artista e do poeta com o engenheiro de computação, desde o início dos computadores, motivou a criação de poemas em computador; o desenvolvimento da tecnologia computacional permitiu ao poeta diferentes tipos de intervenções; a criação de um número significativo de softwares motivou o uso de diferentes editores de textos e de imagens como forma de expressão poética e artística; as interfaces (desktop, janelas, linques, texto, agentes, conforme Steven Johnson) criaram novas relações nos meios eletrônico-digitais; e assim por diante.

As formas de gravação de sons (gravador, disco, cassete, cd, cd-rom, dvd, etc.) devolve ao poeta a origem da poesia (oral, falada para uma pequena platéia) e Ihe dá a possibilidade de "aprisionar" a voz, enquanto formas de registros de imagens, estáticas ou não (fotografia, vídeo, cinema, televisão. holografia), registram o rosto, a paisagem, a moradia, trazendo uma junção da palavra, da imagem, do som e do movimento, reunindo pessoas dos mais diversos locais.

Esses mesmos aspectos transformadores, que foram estudados por Marshall McLuhan como os meios de comunicação como extensões do homem, bem como a cultura da interface, de acordo com conceitos de Steven Johnson, são para o poeta outra fonte de inspiração.

O computador, a Internet e a WWW são tecnologias que também transformam, seduzem e ampliam a expressão poética, pois oferecem o intercâmbio imediato com o mundo (Internet), uma forma de armazenamento de dados que ocupa pouco espaço (computador e WWW), e um grande recurso de expressão gráfica, sonora e de movimento (computador, hardware e software).

A poesia também usa essas tecnologias e tem criado uma grande quantidade de tipos de poesias, desde a poesia permutacional do final dos anos 50 (Théo Lutz, Jean A. Baudot, Nanni Balestrini, etc.) até a poesia com o uso do software Flash. Palavras, sons, imagens e movimentos se unem no ciberespaço e produzem outra poesia, que tem recebido as mais diferentes denominações, 
indicando o tipo de tecnologia computacional utilizando, portanto, denominações "datadas", ou seja, indicando o estágio tecnológico em que esse processo criativo foi realizado: poesia informática, poesia artificial cibernética (Max Bense), infopoesia (Melo e Castro), poesia eletrônica, poesia digital, poesia virtual (Ladislao Pablo Györi), interpoesia (Philadelpho Menezes e Wilton Azevedo), poesia-do-click (David Knoebel), lingu(im)agem (Jim Andrews), poesia das novas mídias (Eduardo Kac), poesia hipertextual, poesia intersignos (Philadelpho Menezes), ciberliteratura (Pedro Barbosa) etc.

Sem ter a intenção de esgotar o assunto, esta introdução objetiva apresentar alguns aspectos da poesia eletrônica e uma série de exemplos dos mais diferentes países. Adotamos a ordem alfabética de autores e um breve comentário sobre cada sítio apresentado.

ANTUNES, Arnaldo - www.arnaldoantunes.com.br - Músico e poeta, Arnaldo Antunes é autor de muitos livros, dentre os quais Tudos, de 1990, que contém suas primeiras experiências de poesia digital. O livro-cd-dvd Nome (1993) é uma obra que mostra o percurso da poesia verbal e visual no meio impresso e uma releitura a partir da linguagem eletrônica do vídeo.

CAMPOS, Augusto de - www.uol.com.br/augustodecampos - Augusto de Campos é um exemplo de poeta e de ser humano que se renova a cada momento. Consagrado como um dos líderes da Poesia Concreta no Brasil, com contribuições também no estudo teórico e nas relações da poesia com as outras artes, é pioneiro da videopoesia no Brasil, com "Pulsar", em 1984, e inicia seus vídeo-clips digitais (poemas animados em computador) em 1992.

CASTRO, E. M. de Melo e - Infopoesia: produções brasileiraswww.ociocriativo.com.br/guests/meloecastro - E. M. de Melo e Castro, um dos líderes da Poesia Experimental Portuguesa na década de 60, é pioneiro da videopoesia em Portugal com "Roda Lume" em 1968, e inicia suas criações poéticas com o computador em 1979. Esta é uma das obras do poeta experimental português por intermédio do uso de editores de imagens como o AdobePhotoshop. Outros exemplos se encontram no livro Algorritmos: 
infopoesias (CASTRO, 1998) e O Caminho do Leve (CASTRO; FERNANDES, 2006).

GARCIA, Álvaro Andrade - Sítio de Imaginação - www.ciclope.art.br Ciclope.art.br é um sítio que traz cultura de um modo geral, vídeo sobre cidades históricas, e poesia, especialmente a de Álvaro Andrade Garcia, que cria poesias verbais, videopoesias e poesia digital.

Poema Visual - Coordenação de Hugo Pontes e Vitor Hugo Manata Pontes http://www.poemavisual.com.br - Sítio existente desde 1996, "Poema Visual" dedica-se à divulgação da poesia visual que migrou para a web, por meio do qual é possível apreciar muitos poetas como: Hugo Pontes, Sebastião Nunes, Joaquim Branco, Avelino de Araújo, Philadelpho Menezes (1960-2000), etc.

PINTO, Regina Célia (editora) - Museu do Essencial e do Além Disso: Arquitetura de Informação e Interface Criativa - www.arteonline.arq.br - Regina Célia Pinto reúne nesse sítio poetas e artistas de muitos países. É uma obra em constante renovação e pode ser considerada uma exposição permanente e renovada do que a arte, a poesia e a tecnologia têm produzido no mundo.

TEODORO, Juliana; VENERA, Alexandre (Org.) - 6x Juliana Teodoro Alexandre Venera - http://www.youtube.com/opioptico\#p/c/20A03EA3F4190950 - Sob a coordenação de Alexandre Venera dos Santos, o aLe, e Juliana Teodoro, este sítio é uma obra hipermidiática interativa, que conta com a participação de seis artistas e poetas: Muriel Frega (Argentina), Douglas Zunino (Brasil), Reiner Strasser (Alemanha), Rosane M. Martins (Brasil), iraN (Brasil) e Clemente Padin (Uruguai).

URIBE, Ana Maria - Tipoemas y Anipoemas - www.vispo.com/uribe/index.html Ana Maria Uribe (1951-2004), da Argentina, trabalhava a letra como expressão poética de origem concreta. Antes de fazer parte dos meios eletrônico-digitais (cd-rom e web), fez muita poesia visual. Sua capacidade de síntese, aliada a um humor e a uma graça encantadoras, realiza uma comunicação especial. 


\section{Exemplos de leituras}

A poesia eletrônica, ou qualquer outra denominação que lhe possa ser dada (computer poetry, poesia numérica, ciberpoesia, poesia digital, tecnopoesia, etc.), é uma continuação dos tipos de fazeres poéticos da segunda metade do século XX. O computador permitiu que muitas experimentações poéticas pudessem ser realizadas, testadas ou complementadas. Ou seja, o nível de produção poética até então existente foi experimentada por intermédio do computador em suas mais diferentes fases. Nos primeiros momentos, em muitos casos, foi apenas migração, transferência ou transposição, mas, em contato com a linguagem dos computadores, o poeta foi descobrindo uma linguagem tecnológica que vem se adaptando à linguagem poética.

É a partir dessa confluência que o tema central deste estudo se configura: a linguagem computacional, nas suas mais diferentes fases, vai produzir um impacto no poeta e ele vai passar a fazer um uso poético dela. Esse foi o tema desenvolvido em A literatura cibernética 1: autopoemas gerados por computador (BARBOSA, 1977), Poética dos meios e arte high tech (CASTRO, 1988), Informatique et Littérature (VUILLEMIN, 1990), Hyperpoems and Hyperpossibilities $^{4}$ (LARSEN, 1992), Cybertext poetry: effects of digital media on the creation of poetic literature (FUNKHOUSER, 1997), Ensaio sobre o texto poético em contexto digital (RISÉRIO, 1998), Digital Poetics: The Making of EPoetries (GLAZIER, 2002), p0es1s: Äesthetik digitaler Poesie / p0es1s: The Aesthetics of Digital Poetry (BLOCK; HEIBACH; WENZ, 2004), Prehistoric Digital Poetry: An Archaeology of Forms, 1959-1995 (FUNKHOUSER, 2007), dentre outros.

Em todas essas publicações, além de uma teorização séria e de esboços de panorama histórico, há sempre análises de poemas e de poetas, nas mais variadas extensões. Como o estudo desse tipo de poesia encontra-se em seus primórdios, faz-se necessário pensar na leitura da poesia digital por meio das

\footnotetext{
${ }^{4}$ Primeira dissertação de mestrado sobre poesia digital nos EUA.
} 
suas dimensões gráficas, visuais, cinéticas e sonoras, pois elas representam a realização daquilo que a palavra poética, no meio oral e/ou impresso, sugeria, um enfoque que vem sendo desenvolvido pela Crítica Literária.

Para facilitar a compreensão inicial da análise, foi feita uma escolha de alguns tipos de poesia e, por meio deles, será possível abordar a leitura da poesia eletrônica sob a dimensão que nela predominar.

As primeiras poesias computacionais foram, a exemplo do texto estocástico de Theo Lutz, em 1959, de "I am that I am", de Brion Gysin, em 1960, e do "Tape Mark I", de Nanni Balestrini, em 1961, experimentações com a tentativa de transposição de palavras, em determinada ordem gramatical (substantivo, verbo, adjetivos, preposições, etc.) e com certa combinação entre cada grupo de palavras. Predominou uma dimensão programática: o uso do computador, antes destinado apenas a cálculos, começa a produzir linguagem. As primeiras experimentações partem de palavras estocadas previamente, que são recombinadas. Trata-se da utilização das técnicas da poesia permutacional e combinatória. As permutações e combinações produzidas eram impressas e, após muitas seleções, chegava-se a um poema computacional. Uma experiência bastante significativa é o trabalho pioneiro de Pedro Barbosa em Portugal, a partir de 1975, que resultou em "Poema de Computador" (BARBOSA, 1996, p. 251-257).

Trazendo alguma semelhança com a "typewriter poetry", na década de 70 , há exemplos de uma relação visual com o uso do computador, como é o caso do poema de Leslie Mezei:

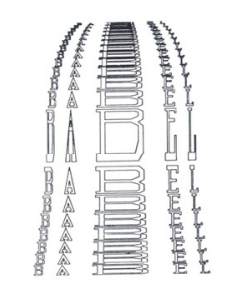

Leslie Gabriel Mezei (Canadá, 1968), a partir de poema de mesmo título de Pedro Xisto (1965) - Babel (in Bailey, 1973, p. 32) 
Embora muitos estudiosos considerem essas experimentações como uma espécie de extensão da poesia concreta, especialmente porque alguns poetas concretos afirmam que a poesia concreta tinha uma vocação para ser hipermidiática, o uso da linguagem programática já começa a explorar a visualidade que se constrói por simulação. Uma extensão desse tipo de tecnoarte-poesia é a arte $\mathrm{ASCI}^{5}$ e a poesia ASCII, cujo exemplo comentaremos mais adiante.

\author{
MÁQUINA \\ Luzes de mais \\ ofuscam os meus olhos. \\ Luzes de menos \\ fazem-me doente. \\ Dêem-me um dispositivo automático \\ para regular o sol \\ ao nascer, no zénite e no poente.
}

E. M. de Melo e Castro (1990, p. 13)

Querer uma máquina reguladora de luzes-palavras, desenhar com palavras, imaginar música escrevendo, transformar palavras em imagens manipuladas eletronicamente, organizar imagens e letras para se tornar um foto-poema - eis algumas das funções utópicas da literatura, pois o poeta quer que o real fique contido na unidimensionalidade da linguagem.

Hoje o poeta conta com a tecnologia computacional que the oferece um único meio, o espaço eletrônico ou ciberespaço, onde ocorre a reunião da palavra, da imagem, do som e da animação.

A palavra falada, depois impressa, transformada em imagem, ou posta ao lado da imagem, vai ser a palavra digital, composta de unidades de texto, gráfico, imagem, som - que somente se tornam possíveis dentro do simbólico espaço

\footnotetext{
${ }^{5}$ Desenhos produzidos apenas com caracteres da tabela ASCII. A arte ASCII foi a maneira encontrada pelos usuários da Internet para ilustrar suas mensagens, já que durante mais de vinte anos a rede tinha capacidade gráfica limitada. A arte ASCIl é muito utilizada em arquivos de assinatura e plan files. Há um ASCII Art Dictionary, organizado por Andreas Freise (1997): www.ascii-art.de.
} 
dos computadores modernos, da Internet e da W W W (DELANY; LANDOW, 1993, p. XI).

A imagem trouxe ao poema a sua "realidade" visual, de certa forma substituindo a descrição, produzindo o que pode ser chamado de poesia visual. As tecnologias eletrônicas e computacionais possibilitaram a inclusão da palavra, do som, da imagem e da animação num mesmo meio e, assim, pôde surgir uma poesia que recebeu diferentes denominações, mas todas englobadas no termo "tecno-poesia".

As relações entre poesia e novas tecnologias podem ser vistas sob vários ângulos. Eis alguns enfoques exemplificados. Se pensarmos em tecnologia como ciência aplicada, o poeta faz negociações semióticas com a tecnologia há muito tempo das mais diferentes maneiras. Por exemplo, o surgimento do telégrafo foi celebrado por poetas, jornalistas e músicos em verso e prosa, conforme publicação no Diário de Notícias (Brasil) de 13 de outubro de 1886 (apud Gontijo, 2004, p. 333):
É notável, hoje em dia, o progresso que tem feito a grande telegraphia.
Pergunta qualquer sujeito
Com Buenos Ayres ligado:
Como va usted?
- Muito bem, muito obrigado, respondem por desafogo.

O surgimento das tecnologias traz, primeiro, um novo conceito e um vocabulário ao poeta, cujo exemplo modesto pode ser o poema acima. $\mathrm{O}$ convívio com o novo oferece recursos expressivos e comunicacionais que podem se incorporar ao fazer poético. Além da incorporação do novo vocabulário e da metáfora, alguns poetas irão intervir nas linguagens tecnológicas para fazer poesia com elas. Dentre as novas tecnologias, está o computador e todos os recursos que ele oferece como máquina e como linguagem. 
Os poetas contemporâneos, mesmo aqueles que optaram pelo meio impresso, já dialogam com as linguagens tecnológicas do seu tempo, às vezes sem se dar conta disso. Tenho observado isso, mas ainda não foi possível fazer um estudo mais aprofundado sobre o assunto.

Nós vivemos com a tecnologia e, de certa forma, precisamos dela para sobreviver na sociedade contemporânea. $O$ tecnopólio, aquele conceito bem explicado por Neil Postman, em Tecnopólio: a rendição da cultura à tecnologia, precisa ser enfrentado.

Um exemplo disso é o poema visual abaixo, de Avelino de Araújo,

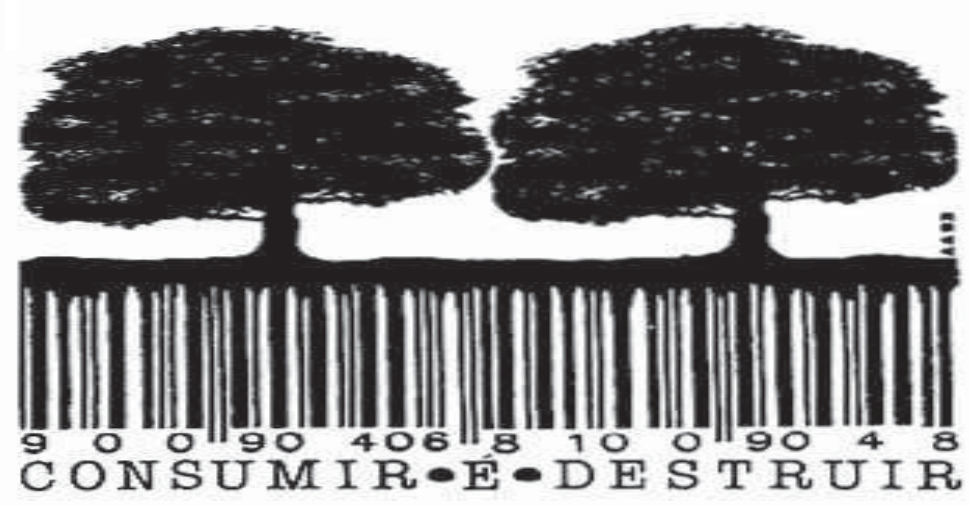

que questiona a tecnologia a partir da sua própria linguagem, o código de barras.

Assim como a poesia defendeu idéias revolucionárias, buscou justiça social, o poeta contemporâneo precisa transgredir essa tecnologia e transformá-la em algo não utilitário, algo estético. O código de barras, embora sirva para indicar o preço de uma mercadoria, pode sofrer a intervenção de um poeta.

Outro exemplo é "Pop Up Poems" de Jim Andrews http://vispo.com/popups/popups.htm: 


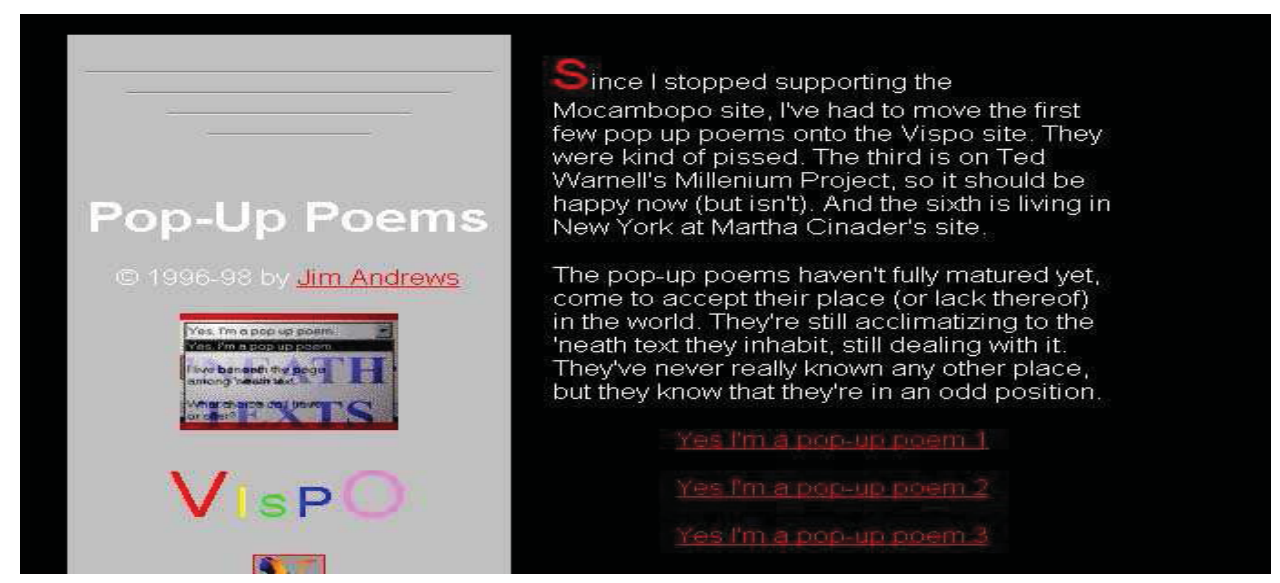

A "pop up", que, em web design, é um recurso para permitir abrir janelas ao longo de um texto, economizando tempo e facilitando consultas, aqui se antropomorfiza e reage com as injustiças que vem sofrendo no meio eletrônico.

\section{Conceito de tecno-arte-poesia}

O resultado das pesquisas, até o presente momento, permitiu chegar a um primeiro conceito de tecno-arte-poesia. A tecno-arte-poesia é um tipo de poesia contemporânea, que mantém e apresenta um vínculo com as poesias existentes anteriormente, tem suas raízes nos procedimentos da poesia modernista das vanguardas do início do século $X X$ e é uma continuação das poesias concreta e visual. Por ter procedimentos experimentais bastante acentuados e predominantes, também é considerada como um desdobramento ou continuação da poesia experimental, uma denominação geral utilizada por criadores e teóricos de vários países.

O percurso dos meios em que a poesia vem sendo apresentada ajuda a compreender essa continuidade que chega à tecno-arte-poesia: depois de ter sido poesia oral e acompanhada de instrumentos musicais na Antiguidade, ela tem existência no meio impresso, isto é, tornou-se bidimensional. Assimilou os recursos das artes (pintura, desenho, escultura, arquitetura, música) e passou a se concretizar no espaço físico, no meio tridimensional, como objeto artístico, à semelhança de um desenho ou de uma pintura (poesia visual) ou de uma escultura (poesia-objeto). Depois, adaptada à linguagem binária dos computadores, tornou-se simulação e foi para o ciberespaço gradativamente, à 
medida que a tecnologia computacional foi se transformando: a execução do programa, antes totalmente apresentada em forma impressa, foi migrando para uma exibição na tela do computador, até tornar-se um texto eletrônico de circulação apenas no meio digital.

Ela é formada por palavras, grafismos, imagens estáticas e/ou imagens animadas e sons: todo esse conjunto é elaborado parcial ou totalmente por processos digitais, portanto, torna-se um texto eletrônico e/ou hipertexto e/ou hipermídia, e passa a existir num arquivo digital ou ciberespaço (e-book, rede digital, nos seus mais diferentes suportes eletrônicos: CD, cd-rom, DVD, pendrive, etc.) e configura-se como um produto cíbrido ${ }^{6}$ desde os seus primórdios.

O entendimento desse tipo de poesia contemporânea passa por um aspecto interdisciplinar e/ou multidisciplinar e/ou transdisciplinar; daí a razão de ser denominada tecnopoesia ou tecno-arte-poesia. Há um predomínio de relações, diálogos ou negociações semióticas com os processos criativos artísticos, de design, tecnológicos, comunicacionais e poéticos.

Em virtude de ser uma poetização das tecnologias digitais, que se transformam constantemente, a denominação para esse tipo de fazer poético apresenta uma variedade que indica o tipo de tecnologia digital utilizada - computer poetry, poesia informática, texto computacional, tecnopoesia, ciberpoesia, poesia cibertextual, tecno-arte-poesia, poesia do clique, poema pop-up, web poesia, poesia hipertextual, poesia hipermídia, etc.

Sua existência ocorre por intermédio da simulação e da mediação poeta / máquina de maneira total, parcial ou por meio de uma relação cíbrida (meios físicos e meios digitais).

A linguagem da poesia digital apresenta uma textualidade eletrônica que, em muitos casos, tem hipertextualidade, hipermidialidade, interatividade. Há

\footnotetext{
${ }^{6}$ Trata-se de um hibridismo que se faz com os componentes da cibercultura.
} 
processos de criação e participação colaborativos, parcerias de autorias e processos coletivos de criação. A partir da existência das redes sociais, a poesia digital ocorre em ambientes virtuais multiusuários. Com o desenvolvimento das tecnologias móveis e sem fio, ela também sofre algumas adaptações e passa a circular nesses meios.

É uma poesia que se transforma com os processos artísticos e de design e, principalmente, com os processos tecnológicos e está vinculada aos estágios da tecnologia e à sua rápida obsolescência, necessitando transformação, mudança e adaptação na velocidade do surgimento de novos equipamentos, hardware e software. Felizmente, nos dias de hoje, muitos programas simuladores de processos digitais desativados, como os emuladores, estão resgatando processos criativos dos pioneiros. Também há programas que convertem as diferentes versões de software e há os que substituem os anteriores e, por isso, já existem obras de recriação de antigas poesias digitais ${ }^{7}$.

A poesia digital tem duas fases principais: a dos computadores isolados e a dos computadores interligados em redes digitais ${ }^{8}$.

O período dos computadores isolados tem início em 1959 com os grandes computadores que usavam diretamente linguagem de programa, ou seja, com pouquíssimas interfaces e o resultado, em forma impressa, era escolhido pelo poeta-programador. O surgimento do computador pessoal trouxe uma maneira mais fácil e individual de trabalhar com programas simples e contou com algumas interfaces, como: mouse e monitor de televisão.

A criação do modem e da WWW gerou o computador em rede e aumentou o ciberespaço, criando uma cibercultura ou second life, que continua se desenvolvendo e se aperfeiçoando até os dias atuais. O computador pessoal e individual tornou-se um computador coletivo e universal. Sítios, blogs e redes

\footnotetext{
${ }^{7}$ O exemplo mais significativo é o resgate de Stochastiche Texte, de Theo Lutz, de 1959, por Johannes Auer.

${ }^{8}$ Pode-se afirmar que uma terceira fase tem início com as tecnologias móveis e sem fio, que ainda se encontra pouco explorada.
}

Texto Digital, Florianópolis, v. 7, n. 2, jul./dez. 2011. ISSNe: 1807-9288 
sociais permitem uma divulgação em tempo real de praticamente tudo na vida das pessoas. O poeta pode publicar seus poemas enquanto estão sendo pensados e escritos e pode aprender rapidamente a usar os mais diferentes programas e poetizá-los. Para fazer isso, ele conta com homepages, blogs, sites, redes sociais e diferentes tipos de tecnologias wireless.

As tecnologias da comunicação (jornal, cinema, rádio, televisão, vídeo) também assimilaram as tecnologias computacionais, ocorrendo miniaturização e potencialização: surgiram as tecnologias móveis, como os telefones celulares e seus derivados, os computadores portáteis (lap top, notebook, netbook) e os ereaders.

A poesia digital é um produto da cibercultura ou da cultura digital e, portanto, pode ser chamada de ciber-arte-poesia ou tecno-arte-poesia.

\section{Referências}

AGUIAR, Fernando. Foto-poema. Encontro, Porto, Portugal, 14 abr. 1991, n 138.

ARAÚJO, Hermete Reis de (Org.). Tecnociência e cultura: ensaios sobre o tempo presente. São Paulo: Liberdade, 1998.

ARAÚJO, Júlio César (Org.). Internet \& ensino: Novos gêneros, outros desafios. Rio de Janeiro: Lucerna, 2007.

; BIASI-RODRIGUES, Bernadete (Org.). Interação na Internet: Novas formas de usar a linguagem. Rio de Janeiro: Lucerna, 2005.

BAILEY, Richard W. (Org.). Computer poems. Drummond Island, Michigan, EUA: Potagannissing Press, 1973.

BARBOSA, Pedro. A Ciberliteratura: criação literária e computador. Lisboa: Cosmos, 1996.

BARTHES, Roland. S/Z. Tradução: Léa Novaes. Rio de Janeiro: Nova Fronteira, 1992.

. Aula. Tradução: Leyla Perrone-Moisés. 9.ed. São Paulo: Cultrix, 1995. 
BLOCK, Friedrich W.; HEIBACH, Christiane; WENZ, Karin (Ed.). p0es1s. Äesthetik digitaler Poesie / The Aesthetics of Digital Poetry. Tradução: Nina Bishara et al. Ostfildern-Ruit, Alemanha: Hatjie Cantz Verlag, 2004.

BRASIL, André; FALCI, Carlos Henrique; ALZAMORA, Geane (Org.). Cultura em fluxo: novas mediações em rede. Belo Horizonte, MG: Ed. PucMinas, 2004.

CAMPOS, Roland de Azeredo. Arteciência: afluência de signos co-moventes. São Paulo: Perspectiva, 2003.

CASTRO, E. M. de Melo e. Trans(a)parências: poesia - I: 1950-1990. Sintra: Tertúlia, 1990.

Algorritmos: infopoemas: 1998. São Paulo: Musa, 1998.

; FERNANDES, João (Coord.). O caminho do leve / The Way to Lightness. Tradução: John Havelda e Sofia Gomes. Porto, Portugal: Museu Serralves, 2006. 303p. Catálogo de exposição, 10 fev.-30 abr. 2006, Museu de Serralves.

CHKLOVSKI, V. A arte como procedimento. In: TOLEDO, Dionisio de Oliveira (Org.). Teoria da Literatura: formalistas russos. Tradução: Ana Mariza Ribeiro et al. Porto Alegre, RS: Globo, 1971. p. 39-56.

COLOMBO, Fausto. Os arquivos imperfeitos: memória social e cultura eletrônica. Tradução: Beatriz Borges. São Paulo: Perspectiva, 1991.

COSTA, Cristina. Ficção, comunicação e mídias. São Paulo: Senac, 2002.

COSTA, Murilo Jardelino da (Org.). A festa da língua: Vilém Flusser. São Paulo: Fundação Memorial da América Latina, 2010.

COSTA, Rogério da. A cultura digital. São Paulo: Publifolha, 2002.

DELANY, Paul; LANDOW, George P. (Ed.). The digital word: text-based computing in the humanities. Massachusets, USA: The MIT Press, 1993.

(Ed.). Hypermedia and Literary Studies. Cambridge, Massachussetts, EUA: The MIT Press, 1994.

DOMINGUES, Diana (Org.). A arte no século XXI: a humanização das tecnologias. Tradução: G. B. Muratore e Diana Domingues. São Paulo: Ed. Unesp, 1997.

(Org.). Arte e vida no século XXI: tecnologia, ciência e criatividade. São Paulo: Unesp, 2003.

(Org.). Arte, ciência e tecnologia: passado, presente e desafios. São Paulo: Ed. UNESP/ Itaú Cultural, 2009. 
FLUSSER, Vilém. A escrita: há futuro para a escrita? Tradução: Murilo Jardelino da Costa. Revisão técnica: Gustavo Bernardo. São Paulo: Annablume, 2010.

FUNKHOUSER, C. T. Prehistoric digital poetry: an archaeology of forms, 19591995. Tuscaloosa, Alabama, EUA: The University of Alabama Press, 2007.

GONTIJO, Silvana. O Livro de Ouro da Comunicação. Rio de Janeiro: Ediouro, 2004.

JOHNSON, Steven. Interface culture: how new technology transforms the way we create and communicate. New York, EUA: Basic Books, 1997.

LANDOW, George P. Hypertext 2.0: The convergence of contemporary Critical Theory and technology. Baltimore, Maryland, USA: The Johns Hopkins University Press, 1997.

Hypertext 3.0: Critical Theory and New Media in an era of globalization. Baltimore, Maryland, EUA: The Johns Hopkins University Press, 2006.

(Ed.). Hyper / Text / Theory. Baltimore, Maryland, USA: The Johns Hopkins University Press, 1994.

LAUFER, Roger; SCAVETTA, Domenico. Texto, hipertexto, hipermídia. Tradução: Conceição Azevedo. Porto: Rês, [199...].

LÉVY, Pierre. Cibercultura. Tradução: Carlos Irineu da Costa. 2.ed. São Paulo: Ed. 34, 1999.

MACHADO, Arlindo. A televisão levada a sério. São Paulo: Senac, 2000.

MACHADO, Irene de Araújo. Gêneros no contexto digital. In: LEÃO, Lucia (Org.). Interlab: labirintos do pensamento contemporâneo. São Paulo: lluminuras / FAPESP, 2002. p. 71-81.

MACIEL, Katia; PARENTE, André (Orgs.). Redes sensoriais: arte, ciência, tecnologia. Rio de Janeiro: Contra Capa, 2003.

MARCUSCHI, Luiz Antonio; XAVIER, Antonio Carlos (Orgs.). Hipertexto e gêneros digitais. Rio de Janeiro: Lucerna, 2005.

MARINHO, Marildes (Org.). Ler e navegar: espaços e percursos da leitura. Campinas, SP: Mercado de Letras / Associação de Leitura do Brasil - ALB, 2001.

MARTINS, Francisco Menezes; SILVA, Juremir Machado da. Para navegar no século XXI: tecnologias do imaginário e cibercultura. 2.ed. Porto Alegre, RS: Sulina / Edipucrs, 2000. 
MCLUHAN, Marshall. A Galáxia de Gutenberg: A formação do homem tipográfico. Tradução: Leônidas Gontijo de Carvalho e Anísio Teixeira. São Paulo: Nacional, 1972.

MOLES, Abraham A. Rumos de uma cultura tecnológica. Tradução: Pérola de Carvalho. São Paulo: Perspectiva, 1973.

- O cartaz. Tradução: Miriam Garcia Mendes. 2.ed. São Paulo: Perspectiva, 2005.

; ANDRÉ, Marie-Luce (Col.). Art et ordinateur. Paris : Casterman, 1971.

; ROHMER, Elisabeth (Col.). Art et ordinateur. Paris: Blusson, 1990.

Afrontamento, 1990a.

. Arte e computador. Tradução: Pedro Barbosa. Porto:

MORAES, Dênis de. O concreto e o virtual: mídia, cultura e tecnologia. Rio de Janeiro: DP\&A, 2001.

NIELSEN, Jakob. Multimedia and hypertext: the Internet and beyond. Boston, EUA: AP Professional, 1995.

PAJARES TOSCA, Susana. Literatura digital: el paradigma hipertextual. Cáceres, Espanha : Universidad de Extremadura, 2004.

PLAZA, Julio; TAVARES, Monica. Processos criativos com os meios eletrônicos: poéticas digitais. São Paulo: Hucitec / FAPESP, 1998.

POE, Edgar Allan. Poemas e ensaios. Tradução: Oscar Mendes e Milton Amado. 2.ed. Rio de Janeiro: Globo, 1987.

POPPER, Frank. Art of Electronic Age. Tradução: Bernard Hemingway. Singapura: Thames \& Hudson, 1993.

QUINTANA, Mário. Velório sem defunto: poemas inéditos. 2.ed. Porto Alegre, RS: 1992.

RIBEIRO, Ana Elisa; VILELA, Ana Maria Nápoles; COURA SOBRINHO, Jerônimo; SILVA, Rogério Barbosa da (Orgs.). Leitura e escrita em movimento. São Paulo: Peirópolis, 2010.

RIDDELL, Alan (Ed.). Typewriter Art. Londres: London Magazine Editions, 1975.

RETTENMAIER, Guilherme; RÖSING, Tãnia (Org.). Questões de literatura na tela. Passo Fundo, RS: Editora UPF, 2010. 
RÖSING, Tânia M. K.; RETTENMAIER, Miguel (Org.). Práticas leitoras para uma cibercilização VI: Diversidade cultural em tempos de globalização. Passo Fundo, RS: Ed. UPF, 2007.

UPF, 2009.

(Org.). Leitura da arte \& arte da leitura. Passo Fundo, RS: Ed.

SANTAELLA, Lucia. Cultura das mídias. São Paulo: Razão Social, 1992.

. Culturas e artes do pós-humano: da cultura das mídias à cibercultura. São Paulo: Paulus, 2003.

- Navegar no ciberespaço: o perfil cognitivo do leitor imersivo. São Paulo: Paulus, 2004.

. Linguagens líqüidas na era da mobilidade. São Paulo: Paulus, 2007.

SCHWARTZ, Lillian Feldman; SCHWARTZ, Laurens R. The Computer Artist's Handbook: concepts, techniques, and applications. New York: W. W. Norton, 1992.

TORRE, Guillermo de. Historia de las literaturas de vanguardia. 3.ed. Madrid, Espanha: Ediciones Guadarrama, 1974. v. I.

. Historia de las literaturas de vanguardia. 3.ed. Madrid, Espanha: Ediciones Guadarrama, 1974a. v. II.

Historia de las literaturas de vanguardia. 3.ed. Madrid, Espanha: Ediciones Guadarrama, 1974b. v. III.

VUILLEMIN, Alain. Informatique et littérature: 1950-1990. Paris: ChampionSlatkine, 1990.

WELLEK, René; WARREN, Austin. Teoria da Literatura. Tradução: José Palla e Carmo. 5. ed. Mira-Sintra, Mem Martins: Europa-America, [s.d.]. 